\title{
Development of simple, scalable protease production from Botrytis cinerea
}

\author{
Rachel A. Self ${ }^{1,2}$ - Mark D. Harrison ${ }^{1,2}$ (D) Valentino S. Te'o Jr. ${ }^{2}$ (I) Steve Van Sluyter ${ }^{3}$
}

Received: 8 December 2021 / Revised: 25 January 2022 / Accepted: 29 January 2022 / Published online: 16 February 2022

(c) The Author(s) 2022

\begin{abstract}
Heat haze-forming proteins are stable during winemaking and are typically removed via adsorption to bentonite. Proteolytic degradation is an alternative method to prevent wine-haze and offers the opportunity to reduce the environmental impacts and labor cost of the process. Herein, we describe the development of a production system for Botrytis cinerea proteases for the enzymatic degradation of heat haze-forming proteins. The effect of culture medium on the secretion of glucan by $B$. cinerea was investigated and methods to inactivate $B$. cinerea laccase in liquid culture medium were assessed. Protease production by $B$. cinerea was scaled up from $50 \mathrm{~mL}$ in shake flasks to $1 \mathrm{~L}$ in bioreactors, resulting in an increase in protease yield from 0.30 to $3.04 \mathrm{~g} \mathrm{~L}^{-1}$. Glucan secretion by $B$. cinerea was minimal in culture medium containing lactose as a carbon source and either lactic or sulfuric acid for $\mathrm{pH}$ control. $B$. cinerea laccases were inactivated by reducing the $\mathrm{pH}$ of culture supernatant to 1.5 for $1 \mathrm{~h}$. B. cinerea proteases were concentrated and partially purified using ammonium sulfate precipitation. SWATH-MS identified aspartic acid protease BcAP8 amongst the precipitated proteins. These results demonstrate a simple, affordable, and scalable process to produce proteases from $B$. cinerea as a replacement for bentonite in winemaking.
\end{abstract}

\section{Key points}

- Isolates of B. cinerea that produce proteases with potential for reducing wine heat-haze forming proteins were identified.

- Media and fermentation optimization increased protease yield tenfold and reduced glucan secretion.

- Low pH treatment inactivated laccases but not proteases.

Keywords Haze-forming proteins $\cdot$ Laccase $\cdot$ Glucan $\cdot$ Fermentation $\cdot$ Enzymes

\section{Introduction}

Bentonite is a clay that is added to wine after fermentation to adsorb heat-haze forming proteins, including chitinases and thaumatin-like proteins (Waters et al. 1996). These proteins come from grapes and aggregate when heated, causing an undesirable haze in the wine (Marangon et al. 2009). While bentonite is commonly used in winemaking (Logan 2018), it has many disadvantages, including the loss of up to

Rachel A. Self

rachel.self@qut.edu.au

1 Centre for Agriculture and the Bioeconomy, Queensland University of Technology, Brisbane, QLD 4000, Australia

2 School of Biology and Environmental Science, Queensland University of Technology, Brisbane, QLD 4000, Australia

3 Department of Biological Sciences, Macquarie University, Sydney, NSW 2109, Australia
$10 \%$ of wine volume without the addition of a filtering step for recovery (Majewski et al. 2011), relatively high costs of labor during treatment and disposal of bentonite waste (Waters et al. 2005), and the loss of finer sensory characteristics from wines (Vela et al. 2017). As a result, there is a need to develop an alternative to bentonite for the removal of heat-haze forming proteins during winemaking.

Alternative techniques for removal of heat-haze forming proteins from wine have been identified, including ultrafiltration (Flores et al. 1990), non-bentonite absorbents (Sarmento et al. 2000) including zirconium oxide (Marangon et al. 2011) and carrageenan (Ratnayake et al. 2019), but none has been adopted by commercial winemakers. The combination of a mixture of Aspergillopepsin I and II (proteases) and flash pasteurization successfully heat-stabilized white wine without adverse effects on sensory characteristics (Marangon et al. 2012) and at lower operating cost relative to the addition of bentonite ( $\operatorname{Logan} 2015)$; however, the 
equipment needed for the additional processing step (flash pasteurization) required for enzyme activation was relatively expensive. Therefore, the ideal protease for removal of heat-haze forming proteins in white wine would be active at normal winemaking temperatures and would not require additional heating or activation. Microbial proteases are used in a wide range of industrial processes and have a wide range of physicochemical characteristics, including optimal temperature (Mienda et al. 2014).

$B$. cinerea is one of the most well-studied fungi (Van Kan 2006) and infects more than 200 crop species (Miclea and Puia 2012), including grape vines. B. cinerea secretes a complex mixture of proteins (Espino et al. 2010; FernándezAcero et al. 2007; González-Fernández et al. 2014; Shah et al. 2009), including metalloproteases and serine proteases, as well as a wide range of enzymes involved in processes such as cell-wall degradation, oxidative burst, and toxin production (González-Fernández et al. 2015). The most abundant proteins in the $B$. cinerea secretome are a family of aspartic acid proteases designated BcAP1-BcAP14 (Ten Have et al. 2004, 2010). BcAP8 alone can represent up to $23 \%$ of the total protein secreted by B. cinerea (Ten Have et al. 2010) and recombinant BcAP8 expressed in transgenic Pichia pastoris has been used to reduce heat-haze in white wine (Van Sluyter et al. 2013). While the use of recombinant BcAP8 to reduce wine heat-haze has been demonstrated, genetically modified products are not accepted in winemaking (Chambers and Pretorius 2010) and a process to produce native $B$. cinerea protease is required.

Relatively large amounts of proteases are secreted when B. cinerea is cultured in liquid medium (González-Fernández et al. 2015), in addition to laccases (Van Kan et al. 2016) and $\beta$-(1,3)(1,6)-D-glucans (Bar-Nun et al. 2007). Laccases are multicopper oxidases that significantly reduce wine quality (Steel et al. 2013; Vignault et al. 2020) and are relatively stable under winemaking conditions. Inactivation of laccases during winemaking has only been observed with the addition of high concentrations of sulfite (> $200 \mathrm{mg} \mathrm{L}^{-1}$ ) or heat-treatment of wine (Claus 2017). Several low-molecular weight compounds have shown to reduce or eliminate laccase production by $B$. cinerea in culture, specifically ethylenediaminetetraacetic acid (EDTA) and calcium chloride $\left(\mathrm{CaCl}_{2}\right)$. The addition of $12 \mathrm{mM}$ EDTA to $B$. cinerea culture medium significantly reduced laccase formation (Bar-Nun et al. 1988) while the addition of 13-20 mM EDTA partially inhibited laccase activity (Sansone et al. 2011; Zouari et al. 1987). The addition of $\mathrm{CaCl}_{2}$ to culture medium significantly decreased detected laccase levels, at relatively low concentrations (80 and $186 \mathrm{mg} \mathrm{L}^{-1}$ respectively). It has further been shown that concentrations of $\mathrm{CaCl}_{2}$ up to $16 \mathrm{~g} \mathrm{~L}^{-1}$ have little negative effect on mycelial growth or total protein secretion in $B$. cinerea (Chardonnet et al. 2000).
The extracellular $\beta$ - $(1,3)(1,6)$-D-glucan "sheath" that $B$. cinerea secretes aids and protects the fungus during host colonization (Gil-ad et al. 2001) and also encapsulates a subset of secreted B. cinerea proteins and lipids (Doss 1999). The presence of this glucan sheath increases viscosity of $B$. cinerea culture media and interferes with subsequent analysis of media chemistry and composition (Pielken et al. 1990). The choice of carbon source used in B. cinerea culture medium influences glucan secretion (Leal et al. 1979). Monosaccharides are commonly used as a carbon sources for B. cinerea fermentation (Ciliberti et al. 2016; Cotoras et al. 2009) and, in such fermentation systems, glucan secretion up to $13 \mathrm{~g} \mathrm{~L}^{-1}$ has been observed (Pielken et al. 1990). However, when lactose (a disaccharide) was used as a carbon source, glucan production was not observed (King et al. 1969).

In the present work, we screened eighty-six wild-type $B$. cinerea isolates for their capacity to secrete protease and laccase on solid growth medium. Three strains were down selected and evaluated for their capacity to secrete protease in liquid medium in shake flasks. The effect of media composition on glucan production was evaluated and media treatments to reduce laccase activity were investigated. Production of the elite $B$. cinerea strain was scaled up to 1 $\mathrm{L}$ and a process was developed to produce a crude protease preparation without laccase activity. The results described herein suggest that $B$. cinerea has potential as a source of protease for removal of heat-haze forming proteins in wine, thereby providing a practical alternative to bentonite.

\section{Materials and methods}

\section{Botrytis cinerea isolates}

Wild-type isolates of $B$. cinerea $(n=16)$ collected from grape vines in Victoria, South Australia, and New South Wales, Australia, were provided by Treasury Wine Estates (Nuriootpa, South Australia). Isolates $(n=5)$ previously collected from SA and Fernhill, VIC, were purchased from AgPath (Vervale, Victoria), and 65 isolates were provided by the Primary Industries and Regions South Australian division of the SA Research and Development Institute (PIRSA-SARDI; Adelaide, South Australia), collected from the Adelaide Hills, SA. B. cinerea RV05 (accession \#BRIP 74,436 a), AH42 (accession \#BRIP 74,435 a), and AH55 (accession \#BRIP 74,434 a) are available from Queensland Plant Pathology Herbarium, Department of Agriculture and Fisheries, Brisbane, Australia.

The B. cinerea reference strain (B05.10; Available from ICMP, New Zealand, Strain no. ICMP 14,168), a haploid wild-type strain originally isolated from grapes (Büttner 
et al. 1994) and now used in laboratories worldwide (Amselem et al. 2011; Liñeiro et al. 2018; Lovato et al. 2019; Quijada-Morin et al. 2018; Srivastava et al. 2020; Zhou et al. 2018), was provided by Dr Jan Van Kan from Wageningen Agricultural University, Wageningen, Netherlands.

\section{Cultivation medium and chemicals}

B. cinerea isolates were cultivated on potato dextrose agar (Oxoid, Hampshire, UK) and sub-cultured from hyphal plugs taken from agar plates or from spore stocks (12.4\% (v/v) glycerol and $0.04 \%$ (v/v) Tween 80 ). Soybean flour type I, $\alpha$-lactose monohydrate, DL-malic acid, L- $(+)$-lactic acid solution $\geq 85 \%$, EDTA, and $\mathrm{CaCl}_{2}$ were purchased from Sigma-Aldrich, St Louis, USA. Sulfuric acid $98 \%$ and $\mathrm{NaOH}$ were purchased from Chem-supply (Gillman, Australia). Food grade ammonium sulfate was purchased from Merck (Darmstadt, Germany) and tartaric acid (food grade) was purchased from McKenzie's, Altona, Australia. All reagents were of analytical grade unless indicated. All solutions were prepared using ultrapure water (Milli-Q system, Merck, Darmstadt, Germany).

Standard soybean flour (SBF) medium contained 2\% $(\mathrm{w} / \mathrm{v})$ soybean flour and $1 \%(\mathrm{w} / \mathrm{v})$ lactose in minimal salts base $\left(1 \mathrm{~g} \mathrm{~L}^{-1} \mathrm{KH}_{2} \mathrm{PO}_{4}, 0.5 \mathrm{~g} \mathrm{~L}^{-1} \mathrm{~K}_{2} \mathrm{HPO}_{4}, 0.5 \mathrm{~g} \mathrm{~L}^{-1}\right.$ $\mathrm{MgSO}_{4} \cdot 7 \mathrm{H}_{2} \mathrm{O}, 0.5 \mathrm{~g} \mathrm{~L}^{-1} \mathrm{KCl}$, and $0.01 \mathrm{~g} \mathrm{~L}^{-1} \mathrm{FeSO}_{4}$ ). The $\mathrm{pH}$ of media was adjusted by the addition of malic or lactic acid (Merck, Darmstadt, Germany).

\section{Screening protease and laccase production from $B$. cinerea on agar plates}

B. cinerea isolates were cultured on skim milk agar (Rajamani and Hilda 1987) at pH 3.5 to identify those isolates that secreted proteases active at the acidic $\mathrm{pH}$ of wine. Skim milk agar contained $2 \%$ (w/v) skim milk powder (Coles, Glen Iris, Australia), $0.5 \%(\mathrm{w} / \mathrm{v})$ yeast extract, and $1.5 \%(\mathrm{w} / \mathrm{v})$ agar, with $0.1 \%$ Triton X-100 (v/v) to limit the spread of fungal hyphae during growth (Nevalainen et al. 2014). Additives were prepared in a minimal salt solution $\left(1 \mathrm{~g} \mathrm{KH}_{2} \mathrm{PO}_{4}\right.$, $0.5 \mathrm{~g} \mathrm{~K}_{2} \mathrm{HPO}_{4}, 0.5 \mathrm{~g} \mathrm{MgSO}_{4} \cdot 7 \mathrm{H}_{2} \mathrm{O}, 0.5 \mathrm{~g} \mathrm{KCl}$, and $0.01 \mathrm{~g}$ $\mathrm{FeSO}_{4}$ per liter in $\mathrm{dH}_{2} \mathrm{O}$ ) (Cotoras et al. 2009). Laccase secretion from isolates was analyzed on guaiacol agar plates, containing potato dextrose agar with $0.02 \%(\mathrm{v} / \mathrm{v})$ guaiacol (Sigma-Aldrich, St Louis, USA) (Kiiskinen et al. 2004).

All plates were inoculated by pushing a $1-\mu \mathrm{L}$ loop of mycelium from a 7- to 14-day-old potato dextrose agar culture of $B$. cinerea into the surface of the agar and incubated at $22{ }^{\circ} \mathrm{C}$. Proteolysis was evident on skim milk agar by a zone of clearing in the opaque agar under, and around the edge of, a growing colony. Laccase secretion was indicated on guaiacol agar plates by a developing color change from faint red to deep brown. Table 1 outlines the scoring metric used to analyze and compare protease and laccase secretion by the $B$. cinerea isolates.

\section{Shake flask fermentation}

Shake flask cultivation was undertaken by inoculating $1 \times 10^{5} \mathrm{~B}$. cinerea spores in $250-\mathrm{mL}$ Erlenmeyer flasks in the dark using $50-\mathrm{mL}$ culture volumes, agitation at $128 \mathrm{rpm}$, and a temperature of $22{ }^{\circ} \mathrm{C}$. All experiments were performed with three biological replicates. Samples of supernatant were collected immediately after inoculation and after 1,3,5, and 7 days of cultivation. Samples of supernatant were immediately snap frozen in liquid $\mathrm{N}_{2}$ and stored at $-80^{\circ} \mathrm{C}$ until analyzed.

Comparison of protease secretion between wild-type $B$. cinerea isolates was performed in SBF medium. Inhibition of laccase secretion by $B$. cinerea in liquid cultures was analyzed with added EDTA and $\mathrm{CaCl}_{2}$. Isolates were cultured in SBF with EDTA added at 20,60, or $80 \mathrm{mM}$, and $\mathrm{CaCl}_{2}$ was added at $1.7,72.1$, or $144.6 \mathrm{mM}(0.186,8$, and $16 \mathrm{~g}$ $\mathrm{L}^{-1}$ ). The impact of addition of organic acids (for $\mathrm{pH}$ control) on glucan secretion by $B$. cinerea was evaluated using SBF medium containing $50 \mathrm{mM}$ malic acid, or either 50 or $100 \mathrm{mM}$ lactic acid.

\section{Protease activity assay}

Protease activity in $B$. cinerea culture medium was quantified using the EnzChek® Protease Assay Kit, green fluorescence, targeting metallo-, serine-, acid-, and sulfhydryl proteases (Thermo-Fisher, Waltham, MA, USA). Briefly, aliquots of fermentation supernatant were diluted (between 1/200 and 1/2000) in $100 \mathrm{mM}$ lactate buffer, $\mathrm{pH}$ 3.5. Standards were
Table 1 Scale used for scoring zone of clearing on skim milk agar and area of color change on guaiacol agar for analysis of protease and laccase production from $B$. cinerea isolates

\begin{tabular}{|c|c|c|c|}
\hline \multicolumn{2}{|c|}{ Skim milk agar } & \multicolumn{2}{|c|}{ Guaiacol agar } \\
\hline Score & Description & Score & Description \\
\hline 0 & No visible zone of clearing & 0 & No visible coloring in agar \\
\hline 1 & Clearing just under colony & 1 & Slight coloring, typically just under colony \\
\hline 2 & Clearing up to $2 \mathrm{~mm}$ from colony & 2 & Stronger and more even coloring to the agar \\
\hline 3 & Clearing $>2 \mathrm{~mm}$ from colony & 3 & Dramatic, dark coloring to the agar \\
\hline
\end{tabular}


prepared using pepsin from porcine gastric mucosa (SigmaAldrich, St Louis, MO, USA) containing 0.39, 0.78, 1.56, $3.13,6.25,12.5,25$, and $50 \mathrm{mg} \mathrm{L}^{-1}$. Samples, standards, and controls $(50 \mu \mathrm{L})$ were analyzed in triplicate on black, flat bottomed 96-well plates (Greiner CELLSTAR®, SigmaAldrich, St Louis, USA). The EnzChek® substrate was kept at $\sim 4{ }^{\circ} \mathrm{C}$ before addition to the microplate and added immediately before analysis ( $50-\mu \mathrm{L}$ volume).

Fluorescence of the reaction was measured every min for $10 \mathrm{~min}$ at $485-\mathrm{nm}$ excitation and $530-\mathrm{nm}$ emission on a FLUOstar OPTIMA microplate reader (BMG Labtech, Ortenberg, Germany). A second-order polynomial standard curve was calculated from the fluorescent kinetics of pepsin standards, and protease activity in the $B$. cinerea culture medium was calculated as pepsin equivalents (corrected for dilution factor). The protease activity was averaged across three biological replicates, and the standard deviation calculated using Microsoft Excel software (Redmond, USA).

\section{Laccase activity assays}

Laccase activity in $B$. cinerea medium was measured using an adaptation of the method described by Li et al. (2008) using guaiacol as a substrate. Briefly, a $2 \mathrm{mM}$ solution of guaiacol was prepared in $10 \mathrm{mM}$ acetate buffer, $\mathrm{pH}$ 3.5. Subsamples of culture supernatant were diluted with $10 \mathrm{mM}$ acetate buffer, $\mathrm{pH}$ 3.5. Sub-samples of diluted culture supernatant $(33 \mu \mathrm{L})$ were mixed thoroughly with $2 \mathrm{mM}$ guaiacol solution $(167 \mu \mathrm{L})$ in 96 -well microplates. The mixtures were incubated at room temperature $\left(\sim 22^{\circ} \mathrm{C}\right)$ for $2 \mathrm{~h}$ and the absorbance at $544 \mathrm{~nm}$ was measured using a FLUOstar OPTIMA microplate reader (BMG Labtech, Ortenberg, Germany). The absorbance at $544 \mathrm{~nm}$ in microplate wells containing aliquots $(33 \mu \mathrm{L})$ of $10 \mathrm{mM}$ acetate buffer, $\mathrm{pH}$ 3.5 , was averaged and subtracted from the absorbance measured in microplate wells containing sub-samples of diluted culture supernatant. The laccase activity in aliquots (33 $\mu \mathrm{L}$ ) of Rhus vernicifera laccase (Sigma-Aldrich, St Louis, USA) solutions of known concentration was measured and the results used to determine the laccase activity in diluted culture supernatant. Aliquots of sterile culture supernatant $(33 \mu \mathrm{L})$ and grape juice were analyzed as negative controls in each laccase activity assay. All samples were analyzed in triplicate and laccase activity was presented as a mean with a standard deviation.

Re-activation of $B$. cinerea laccases was evaluated using the $2 \mathrm{mM}$ guaiacol solution described above. Briefly, subsamples of $B$. cinerea fermentation media and crude protease preparations that had been treated to deactivate laccase were diluted 1/20 using Chardonnay grape juice. Aliquots $(33 \mu \mathrm{L})$ of diluted fermentation media and crude protease preparations were mixed with $2 \mathrm{mM}$ guaiacol solution (167 $\mu \mathrm{L}$ ) in 96-well microplates, and the absorbance at $544 \mathrm{~nm}$ was measured. The microplates were incubated at $24{ }^{\circ} \mathrm{C}$ overnight $(\sim 18 \mathrm{~h})$ and the absorbance at $544 \mathrm{~nm}$ in each microplate well was measured. The change in absorbance over $24 \mathrm{~h}$ was used to identify samples in which laccase activity was present. Results were blank corrected against pure Chardonnay grape juice before calculating the average and standard deviation.

\section{Bioreactor fermentation}

New Brunswick TM Bioflo®/CelliGen $® 115$ Fermenter and Bioreactor systems (Eppendorf 2012) were used to scale protease production to $1 \mathrm{~L}$. Fermenters were operated in batch mode in heat-blanketed borosilicate vessels, with a working volume of $800 \mathrm{~mL}$ in $1 \mathrm{~L}$ bioreactors. Fermentation media consisted of $2 \%(\mathrm{w} / \mathrm{v})$ soybean flour, $1 \%(\mathrm{w} / \mathrm{v})$ lactose, and $100 \mathrm{mM}$ lactic acid in minimal salts medium and were sterilized at $121{ }^{\circ} \mathrm{C}$ for $60 \mathrm{~min}$. Lactose solution $\left(1 \mathrm{~g} \mathrm{~L}^{-1}\right)$ was sterilized at $121{ }^{\circ} \mathrm{C}$ for 15 min separately to the fermentation media to minimize caramelization. Foaming during fermentation was controlled by the addition of Struktol ${ }^{\circledR}$ J 673 A anti-foam (Schill + Seilacher "Struktol" $\mathrm{GmbH}$, Hamburg, Germany) as required, and fermentation medium $\mathrm{pH}$ was maintained by the addition of $2 \mathrm{~N}$ lactic or $2 \mathrm{~N}$ sulfuric acid, and $3 \mathrm{~N} \mathrm{KOH}$ or $3 \mathrm{~N} \mathrm{NaOH}$. One-way ANOVA statistical analyses were performed using Microsoft Excel software (Redmond, USA).

\section{Bioreactor operating conditions}

Bioreactors were operated under the following baseline conditions: agitation $300 \mathrm{rpm}, \mathrm{pH}$ (maximum) 4.0, aeration at $1.0 \mathrm{VVM}$ (0.8 SLPM), $\mathrm{dO}_{2}$ (minimum) $20 \%$, and temperature $24{ }^{\circ} \mathrm{C}$. A cascade was set to control $\mathrm{dO}_{2}$ by increasing agitation to a maximum of $500 \mathrm{rpm}$ and aeration rate to maximum of 2 VVM (vessel volume per minute) (1.6 SLPM (standard liters per minute)).

\section{Laccase inactivation}

The inactivation of laccase at low $\mathrm{pH}$ was analyzed by dropwise addition of ice-cold sulfuric acid (1 M; Chem-supply, Seventeen Mile Rocks, Australia) to portions of $B$. cinerea culture supernatant. Addition was performed on ice to prevent heat denaturation of proteases, and $\mathrm{pH}$ was constantly monitored while the supernatant was stirred. A volume of water equivalent to the volume of added acid was added to control samples to account for sample dilution. Low $\mathrm{pH}$ samples were kept at $4{ }^{\circ} \mathrm{C}$ for $1 \mathrm{~h}$ to allow time for inactivation of laccase. Samples were placed back onto ice and the $\mathrm{pH}$ returned to 4 with the addition of ice-cold $1 \mathrm{M} \mathrm{NaOH}$ (Chem-supply, Seventeen Mile Rocks, Australia). All analyses were performed in triplicate. 


\section{SDS-PAGE analysis}

Proteins were precipitated from supernatant samples using the method described by Wessel and Flügge (1984), and reconstituted in $40 \mu \mathrm{L}$ master mix containing $(\mathrm{v} / \mathrm{v})$ $70 \% \mathrm{dH}_{2} \mathrm{O}, 25 \% 4 \times \mathrm{NuPAGE}^{\mathrm{TM}}$ lithium dodecyl sulfate sample buffer (Thermo-Fisher, Waltham, MA, USA), and $5 \% \beta$-mercaptoethanol ( $\geq 99 \%$; Merck, Darmstadt, Germany). Samples were heated at $90{ }^{\circ} \mathrm{C}$ for 5 min and centrifuged at $8000 \mathrm{rpm}$ for $5 \mathrm{~min}$ at $8{ }^{\circ} \mathrm{C}$ to pellet insoluble contents. Samples were loaded onto 15 -well Bolt ${ }^{\circledR}$ $4-12 \%$ Bis-Tris plus gels (Thermo-Fisher, Waltham, MA, USA) and resolved by electrophoresis at $90 \mathrm{~V}$ for 40 min. SeeBlue ${ }^{\mathrm{TM}}$ Plus2 Pre-stained Protein Standard (Thermo-Fisher, Waltham, MA, USA) or Precision Plus Protein Dual Color Standard (Bio-Rad, Hercules, CA, USA) $(5 \mu \mathrm{L})$ was resolved on each gel to enable estimation of protein molecular mass. Gels were electrophoresed in 1X Bolt巴 MES SDS Running Buffer (Thermo-Fisher, Waltham, MA, USA) in a Mini Gel Tank (Thermo-Fisher, Waltham, MA, USA) with $10 \mathrm{mg}$ sodium metabisulfite added to gel tank reservoir to improve definition of protein bands. Gels were fixed with $10 \%(\mathrm{v} / \mathrm{v})$ acetone, $40 \%(\mathrm{v} / \mathrm{v})$ ethanol with agitation for $15 \mathrm{~min}$, then stained overnight in QC Colloidal Coomassie Stain (Bio-Rad, Hercules, CA, USA) and de-stained for $3 \mathrm{~h}$ with at least 3 changes of $\mathrm{dH}_{2} \mathrm{O}$.

Stained gels were placed onto a light box for photographing with a Samsung (Suwon, Korea) mobile phone camera. Pictures of gels were cropped, changed to black and white, sharpened (+ 10 contrast, +10 brightness), and annotated using paint.net software (available for free download at https://www.getpaint.net/).

\section{Analyzing ammonium sulfate precipitation of $B$. cinerea secreted proteins}

Precipitation of $B$. cinerea proteases was analyzed at 0 , 40,60 , and $80 \%(\mathrm{w} / \mathrm{v})$ saturation of ammonium sulfate, in triplicate. Ammonium sulfate (Merck, Darmstadt, Germany) was ground into a fine powder with a mortar and pestle before use to increase the rate of dissolution (Burgess 2009). Ammonium sulfate was incrementally added to $10-\mathrm{mL}$ volumes of protease-containing supernatant (with laccase inactivated by $\mathrm{pH}$ reduction). Samples were kept on ice for the duration of ammonium sulfate addition to prevent protease denaturation, and supernatants were stirred gently ( $200 \mathrm{rpm})$ until the ammonium sulfate was fully dissolved. Proteases were precipitated from solution overnight at $4{ }^{\circ} \mathrm{C}$ and then collected by centrifugation at $10,000 \mathrm{rpm}$ for $30 \mathrm{~min}$ at $0{ }^{\circ} \mathrm{C}$. Precipitated proteases were

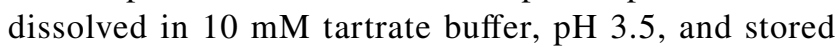

at $-80{ }^{\circ} \mathrm{C}$. Larger scale precipitation was analyzed with $100-\mathrm{mL}$ volumes at $80 \%$ ammonium sulfate saturation, using the method described above.

\section{Protein mass spectrometry and data analysis}

The secreted $B$. cinerea proteins precipitated by ammonium sulfate and re-dissolved in tartrate buffer were identified by Sequential Window Acquisition of All Theoretical Mass Spectra (SWATH-MS) data-independent acquisition as per the method described by Chemonges et al. (2017). Briefly, five volumes of acetone were added to $B$. cinerea protein solutions and the mixtures were stored at $4{ }^{\circ} \mathrm{C}$ for $16 \mathrm{~h}$.

Urea-ammonium bicarbonate buffer ( $8 \mathrm{M}$ urea in $100 \mathrm{mM}$ ammonium bicarbonate) was added to bovine serum albumin protein standards and B. cinerea protease samples to solubilize proteins. Aliquots of solubilized protein $(10 \mu \mathrm{g})$ were mixed with $10 \mathrm{mM}$ dithiothreitol $(1 \mu \mathrm{L}$, dithiothreitol; $5 \mathrm{mM}$ final concentration) to reduce sulfide bonds and incubated at room temperature $\left(\sim 22{ }^{\circ} \mathrm{C}\right)$ for $1 \mathrm{~h}$. The resulting reduced cysteines were alkylated by the addition of $1 \mu \mathrm{L} 55 \mathrm{mM}$ iodoacetamide in $100 \mathrm{mM}$ ammonium bicarbonate $(14 \mathrm{mM}$ final concentration) and incubated in the dark, at room temperature for $20 \mathrm{~min}$. The alkylation reactions were stopped by the addition of $3 \mu \mathrm{L} 10 \mathrm{mM}$ dithiothreitol dissolved in ammonium bicarbonate and the final urea concentration in the samples was reduced below $1 \mathrm{M}$ by the addition of $100 \mathrm{mM}$ ammonium bicarbonate buffer. $\mathrm{C}_{18}$ membrane (Thermo-Fisher, Waltham, MA, USA) was conditioned by addition of $50 \%(\mathrm{v} / \mathrm{v})$ acetonitrile/ $0.1 \%(\mathrm{v} / \mathrm{v})$ trifluoroacetic acid, equilibrated with $0.1 \%(\mathrm{v} / \mathrm{v})$ trifluoroacetic acid, and used to desalt $B$. cinerea peptides. $B$. cinerea peptides were eluted from the membrane with $10 \mu \mathrm{L}$ of $50 \%(\mathrm{v} / \mathrm{v})$ acetonitrile iRT peptide buffer. Peptide mixtures were analyzed on a TripleTOF® 6600 + mass spectrometer (SCIEX, Mt Waverley, Australia). Peptides were eluted with either a 9.5-min gradient in the 25 -min method (for quality control samples) or a 40-min gradient in the 65-min method (B. cinerea protease samples), with mobile phases $\mathrm{A}$ and $\mathrm{B}$ at a constant flow rate of $300 \mathrm{~nL} \mathrm{~min}{ }^{-1}$. The proportions of solvents A and $\mathrm{B}$ were adjusted at specified time-points during the 25 - and 65-min methods as follows: (i) 25-min method: 0, 5, 7, 9.5, 10.2, and 20 min corresponding to $95,60,10,10,95$, and $95 \%$ of solvent A and (ii) 65-min method: 0, 30, 35, 40, 49, 50 , and 60 min corresponding to $98,60,35,10,10,98$, and $98 \%$ of solvent A. Dynamic exclusion was set at 3 or $9 \mathrm{~s}$ to account for the difference in chromatographic peak width between the 25- and 60-min methods.

Eluted peptides were subjected to a cyclic data-independent acquisition using even isolation windows SWATH-MS ${ }^{\mathrm{TM}}$ acquisition 65-min method (SCIEX, Mt Waverley, Australia), as previously described (Gillet et al. 2012). Specifically, survey scan data (MS) was acquired for $0.08 \mathrm{~s}$ followed 
by MS/MS on all precursors within a selected isolation window in a cyclic manner using an accumulation time of $0.08 \mathrm{~s}$ per individual SWATH-MS window. Thirty-six overlapping windows, each $26 \mathrm{~m} / \mathrm{z}$ units wide, were used to cover the peptide ions in a range of 350-1250 m/z which resulted in the cycle time of $3 \mathrm{~s}$. Fragment ions were recorded in a high sensitivity mode and in a range of $100-1800 \mathrm{~m} / \mathrm{z}$. Given the peptide chromatographic peaks were $\sim 18$-s wide, the above parameters allowed the collection of at least 6 data points for each chromatographic peak to ensure accurate quantitation.

A peptide database was created by downloading canoni$\mathrm{cal}$ and isoform protein sequences for $B$. cinerea in FASTA format from the UniProt website (www.uniprot.org; accessed 19/11/2018). Indexed retention time (iRT) peptides (adapted from Escher et al. (2012); Supplemental Table S1) and common contaminant sequences from the common Repository of Adventitious Proteins, cRAP (http://www.thegpm.org/crap/; provided by Central Analytical Research Facility, Queensland University of Technology, Brisbane, Australia) were added to the file. Spectral data from data-dependent analysis of quality control sample was then analyzed against $B$. cinerea protein database using ProteinPilot software (V5.0, ABSciex, Framingham, MA, USA). A background library of B. cinerea peptides was built using Skyline Daily software (MacCoss Lab Software, Seattle, WA, USA), and B. cinerea protease samples imported for identification. Any peptide groups with less than 2 peptide matches were removed. The identified list of proteins was exported and compared against the UniProt database (https://www.uniprot.org/). Specifically, the identified UniProt entry name for each protein group was searched again in UniProt, then any similar proteins with $100 \%$ identity match from $B$. cinerea were checked for a more descriptive identification. For example, a "putative aspartic protease protein" was identified by the original search but was subsequently identified as Bcap8 with a $100 \%$ match in the "similar proteins" section.

\section{Results}

\section{Evaluating wild-type $B$. cinerea isolates for laccase and protease production}

Agar plate assays Eighty-six wild-type isolates of $B$. cinerea were analyzed for protease production on skim milk agar, and for laccase production on guaiacol agar. The scoring system for zones of clearing in skim milk agar, from the cleavage of casein by secreted proteases, provided a semiquantitative analysis for comparison and down-selection of B. cinerea isolates (Fig. 1A). This resulted in the identification of three $B$. cinerea isolates with strong protease production for continuing experimentation; RV05 isolated in

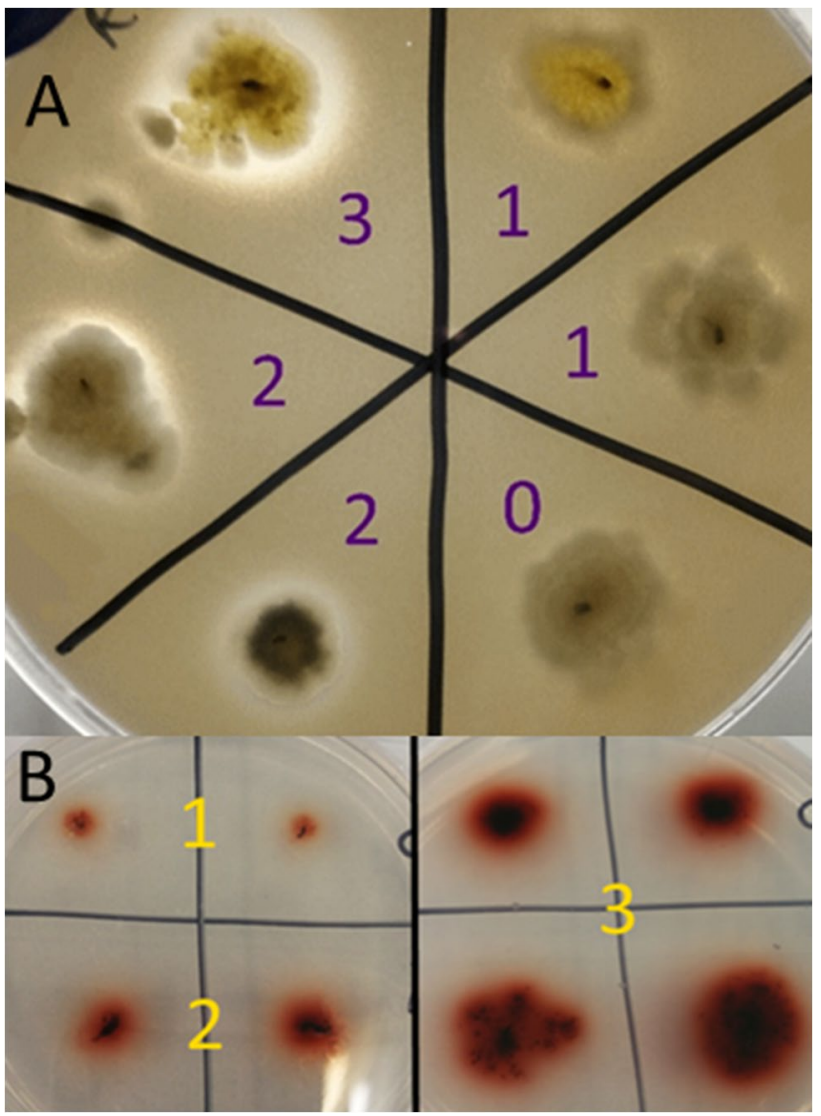

Fig. 1 A $B$. cinerea isolates growing on skim milk agar plates for semi-quantitative comparison of protease production. Numbers indicate the score allocated to the zone of clearing produced by secretion of proteases from each isolate. $\mathbf{B}$ B. cinerea isolates growing on guaiacol agar plates for semi-quantitative comparison of laccase production. Numbers indicate the score allocated to the coloring of the media produced by oxidation of guaiacol from the secretion of laccase

Robin Vale, Victoria, and AH42 and AH55 isolated from Adelaide Hills, South Australia. Scoring of the progressive red/brown color change of guaiacol agar during growth of $B$. cinerea isolates also enabled a robust comparison of laccase production between isolates (Fig. 1B), though no isolate that produced both strong levels of proteases and low levels of laccase (an ideal occurrence) was identified.

Comparison of protease production in shake flask cultures The three elite $B$. cinerea isolates identified by skim milk agar assay were cultured in $250-\mathrm{mL}$ shake flasks containing SBF medium. Each experiment was repeated three times, with three biological replicates per experiment. Proteases produced by the isolates were quantified by EnzChek ${ }^{\circledR}$ Protease Assay, identifying B. cinerea RV05 as the elite protease producing strain in every experiment (Table 2). Furthermore, B. cinerea RV05 produced at least 
Table 2 Results of EnzChek ${ }^{\circledR}$ assay for analysis of protease activity from $B$. cinerea isolates grown in soybean flour medium in $250-\mathrm{mL}$ shake flask culture

\begin{tabular}{llll}
\hline B. cinerea isolate & Protease $\left(\mathrm{g} \mathrm{L}^{-1}\right)$ & \\
\hline AH42 & $0.07 \pm 0.01$ & $0.12 \pm 0.06$ & $0.01 \pm 0.02$ \\
AH55 & $0.04 \pm 0.02$ & $0.09 \pm 0.03$ & $0.01 \pm 0.01$ \\
RV05 & $0.31 \pm 0.01$ & $0.35 \pm 0.08$ & $0.15 \pm 0.04$ \\
\hline
\end{tabular}

fourfold more protease than B. cinerea AH42 or AH55 in all three replicated experiments.

\section{Optimizing B. cinerea protease and laccase production in shake flask cultures}

Analyzing laccase inhibition by EDTA and $\mathrm{CaCl}_{2}$ Inhibition of laccase production (while maintaining strong protease production) by $B$. cinerea RV05 was analyzed in $250-\mathrm{mL}$ shake flask cultures, by the addition of 20,60 , and $100 \mathrm{mM}$ EDTA, and malic acid for $\mathrm{pH}$ reduction. Quantification of laccase production was performed with the guaiacol assay, and results indicate that laccase was produced by $B$. cinerea RV05 at all addition rates of EDTA (Fig. 2a). Protease production was also evident in shake flasks containing EDTA and malic acid, though at lower amounts than controls containing no EDTA (Table 3).

The preparation of SBF media with EDTA and malic acid resulted in a $\mathrm{pH}$ of 3 or less after autoclaving, so laccase production by $B$. cinerea isolates in SBF medium with EDTA only (no malic acid) was analyzed. The resulting cultures were at desired $\mathrm{pH} 3.5$, though laccase was still recorded at every sampling point (Fig. 2b). Furthermore, the removal of malic acid from shake flasks containing EDTA greatly reduced protease production from $B$. cinerea RV05 (Table 3), so EDTA was deemed unsuitable for inhibition of laccase production.

Inhibition of laccase production by $B$. cinerea RV05 was analyzed in $250-\mathrm{mL}$ shake flask cultures, with the addition
Table 3 Maximum protease activity in medium from $B$. cinerea RV05 250-mL shake flask fermentations, analyzed by EnzChek® assay

\begin{tabular}{llll}
\hline Description & Additive & $\begin{array}{l}\text { Concentra- } \\
\text { tion }(\mathrm{mM})\end{array}$ & $\begin{array}{l}\text { Maximum } \\
\text { protease }(\mathrm{g} \\
\left.\mathrm{L}^{-1}\right)\end{array}$ \\
\hline EDTA and malic acid & EDTA & 0 & $0.17 \pm 0.1$ \\
& & 20 & $0.04 \pm 0.0$ \\
& & 60 & $0.08 \pm 0.0$ \\
EDTA & & 100 & $0.04 \pm 0.0$ \\
& EDTA & 20 & $0.00 \pm 0.0$ \\
& & 60 & $0.00 \pm 0.0$ \\
$\mathrm{CaCl}_{2}$ & & 100 & $0.01 \pm 0.0$ \\
& $\mathrm{CaCl}_{2}$ & 1.68 & $0.24 \pm 0.0$ \\
& & 72.08 & $0.30 \pm 0.1$ \\
& & 144.16 & $0.25 \pm 0.0$ \\
\hline
\end{tabular}

of $1.68,72.08$, and $144.16 \mathrm{mM} \mathrm{CaCl}_{2}$. Guaiacol assay analysis identified that laccase was produced at every addition rate of $\mathrm{CaCl}_{2}$, and at increasing amounts in the shake flasks containing 1.68 and $72.08 \mathrm{mM} \mathrm{CaCl}_{2}$ (Fig. 3). Shake flasks containing $144.16 \mathrm{mM} \mathrm{CaCl}_{2}$ showed a comparatively reduced rate of laccase production, and protease production remained strong in all shake flasks containing $\mathrm{CaCl}_{2}$ (Table 3). However, laccase needed to be completely inhibited for these methods to be successful, so $\mathrm{CaCl}_{2}$ was not suitable for inhibition of laccase production in $B$. cinerea.

\section{Comparison of elite wild-type $B$. cinerea isolate to laboratory} reference strain A laboratory reference isolate, $B$. cinerea B05.10, was introduced to compare protease production with elite wild-type isolate, $B$. cinerea RV05. EnzChek ${ }^{\circledR}$ Protease Assay was used to analyze protease production in SBF medium in three separate experiments (SBF 1, 2, and 3), with three biological replicates per experiment. In every experiment, $B$. cinerea RV05 produced higher maximum protease amounts than $B$. cinerea B05.10 (Table 4),
Fig. 2 Laccase activity in soybean flour medium plus EDTA from $B$. cinerea isolate RV05, showing the end-point absorbance of guaiacol assay over time. Panel a shows results of soybean flour medium in 250-mL shake flasks with malic acid added for $\mathrm{pH}$ control, while panel $\mathbf{b}$ shows results with no malic acid added
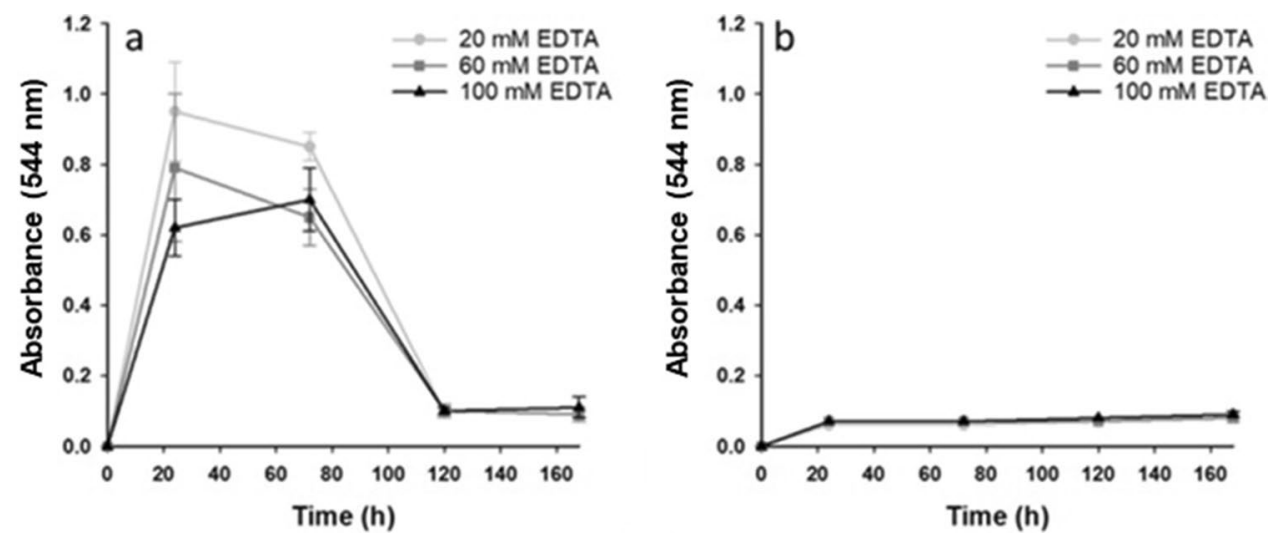


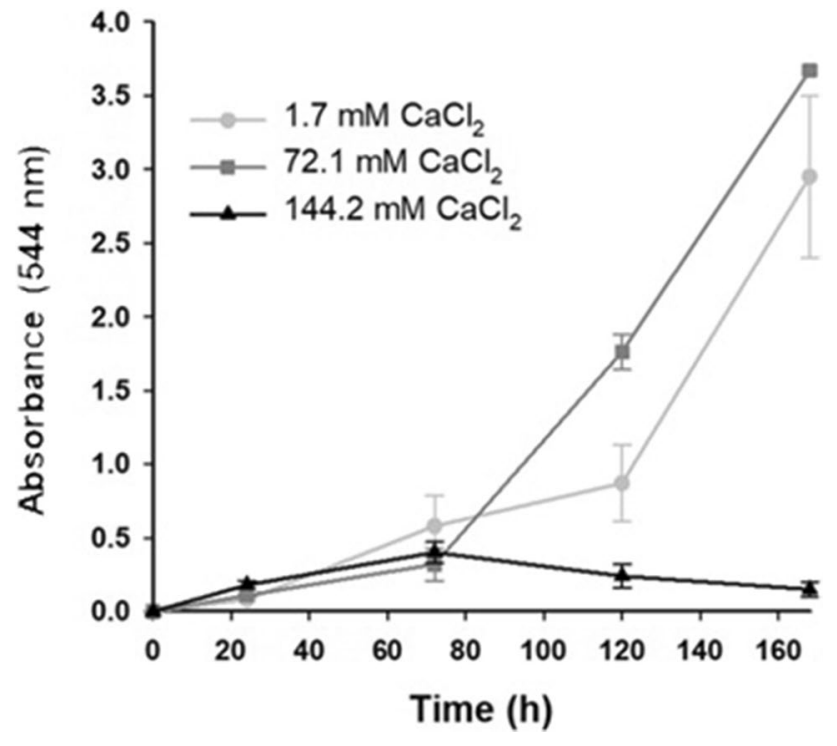

Fig. 3 Laccase activity in soybean flour medium plus $\mathrm{CaCl}_{2}$ from $B$. cinerea isolate RV05, showing the end-point absorbance of guaiacol assay over time

Table 4 Maximum protease activity in medium from $250-\mathrm{mL}$ fermentation of B. cinerea RV05 and B05.10, analyzed by EnzChek ${ }^{\circledR}$ assay

\begin{tabular}{lll}
\hline Experiment & $\begin{array}{l}\text { B. cinerea } \mathrm{RV05}(\mathrm{g} \\
\left.\mathrm{L}^{-1}\right)\end{array}$ & $\begin{array}{l}\text { B. cinerea } \\
\mathrm{B} 05.10(\mathrm{~g} \\
\left.\mathrm{L}^{-1}\right)\end{array}$ \\
\hline SBF 1 & $0.17 \pm 0.01$ & $0.05 \pm 0.01$ \\
$\mathrm{SBF} 2$ & $0.19 \pm 0.02$ & $0.05 \pm 0.01$ \\
$\mathrm{SBF} 3$ & $0.29 \pm 0.06$ & $0.10 \pm 0.02$ \\
Lactic acid $50 \mathrm{mM}$ & $0.15 \pm 0.03$ & $0.10 \pm 0.02$ \\
Lactic acid $100 \mathrm{mM}$ & $0.17 \pm 0.03$ & $0.12 \pm 0.02$ \\
Malic acid $50 \mathrm{mM}$ & $0.12 \pm 0.06$ & $0.12 \pm 0.06$ \\
\hline
\end{tabular}

${ }^{1}$ The data presented for SBF 1, 2, and 3 were from experimental replicates, while the data presented from SBF media containing added lactic and malic acid were from a single experiment and three biological replicates

indicating that $B$. cinerea RV05 was the elite strain for protease production in $250-\mathrm{mL}$ shake flask cultures.

\section{Optimizing liquid medium to reduce glucan produc-} tion When analyzing the inhibition of laccase by EDTA, addition of malic acid to SBF shake flask cultures resulted in a more viscous culture medium when compared to the shake flasks to which no malic acid was added. Reduction in glucan production was investigated by adding lactic acid (another acid produced in the winemaking process), while maintaining strong protease production from both $B$. cinerea RV05 and B05.10. A significant reduction in the viscosity of culture medium was observed with 50 and $100 \mathrm{mM}$ lactic acid added to SBF medium, assessed by the ease of sample collection and the movement of culture medium when swirled in a flask. Maximum protease production from $B$. cinerea RV05 was observed in culture medium containing $100 \mathrm{mM}$ lactic acid in comparison to malic acid (Table 4), though little difference was observed between acids for $B$. cinerea $\mathrm{B} 05.10$. Based on the strong production of protease and reduced culture viscosity in shake flasks, $100 \mathrm{mM}$ lactic acid was identified as the superior acid for $\mathrm{pH}$ reduction in B. cinerea shake flask cultures.

\section{Scaling and optimizing protease production from $B$. cinerea RV05 in 1-L bioreactors}

Protease production from $B$. cinerea isolates was scaled from $250-\mathrm{mL}$ shake flasks to 1 -L bioreactor vessels. $B$. cinerea RV05 was used for initial testing due to its strong protease production in small-scale experiments. Fermentation 1 was performed with conditions analogous to small-scale experiments, i.e., no $\mathrm{pH}$ control. B. cinerea RV05 produced a maximum of $0.83 \pm 0.1 \mathrm{~g} \mathrm{~L}^{-1}$ protease (Table 5), a marked increase from maximum protease amounts observed in small-scale experiments.

Fermentation 2 was operated with $\mathrm{pH}$ control, and $2 \mathrm{~N}$ $\mathrm{H}_{2} \mathrm{SO}_{4}$ and $3 \mathrm{~N} \mathrm{NaOH}$ to maintain the $\mathrm{pH}$ at 3.5. Protease production from $B$. cinerea $\mathrm{RV} 05$ was again greater than the amounts observed in small-scale experiments. However, the continual addition of acid and base to maintain a $\mathrm{pH}$ of 3.5 resulted in a volume increase from 0.8 to over $1.0 \mathrm{~L}$ by the end of the fermentation. Fermentation 3 was maintained at a $\mathrm{pH}$ range of 3.5 to 4.0 , with only the acid pump activated to maintain the $\mathrm{pH}$ below 4 , and lactic acid for $\mathrm{pH}$ reduction. The resulting maximum protease amount was similar to that observed in fermentation 1 , at $0.78 \pm 0.0 \mathrm{~g} \mathrm{~L}^{-1}$. The culture medium also became increasingly viscous as the fermentation continued, from increased glucan production from $B$. cinerea.

Fermentation 4 with $B$. cinerea RV05 was performed with $\mathrm{H}_{2} \mathrm{SO}_{4}$ for $\mathrm{pH}$ control, and the acid pump alone used for $\mathrm{pH}$ maintenance. The removal of lactic acid resulted in a

Table 5 Maximum protease activity in media from 1-L $B$. cinerea RV05 and B05.10 fermentation, analyzed by EnzChek ${ }^{\circledR}$ assay

\begin{tabular}{lll}
\hline Description & B. cinerea strain & Protease $\left(\mathrm{g} \mathrm{L}^{-1}\right)$ \\
\hline Fermentation 1 & RV05 & $0.83 \pm 0.1$ \\
Fermentation 2 & RV05 & $0.52 \pm 0.0$ \\
Fermentation 3 & RV05 & $0.78 \pm 0.0$ \\
Fermentation 4 & RV05 & $3.04 \pm 0.2$ \\
Fermentation B1 & B05.10 & $2.60 \pm 0.3$ \\
Fermentation B2 & B05.10 & $1.75 \pm 0.0$ \\
Fermentation B3 & B05.10 & $3.60 \pm 0.9$ \\
\hline
\end{tabular}


marked decrease in the viscosity of the culture medium, and the highest maximum protease production from $B$. cinerea RV05 was recorded, at $3.04 \pm 0.2 \mathrm{~g} \mathrm{~L}^{-1}$.

While optimizing conditions for 1-L bioreactors, a fault with a $\mathrm{pH}$ probe resulted in a drastic $\mathrm{pH}$ drop in the culture medium from over addition of acid, resulting in a culture medium below $\mathrm{pH}$ 1.5. The $\mathrm{pH}$ was corrected, and the fermentation run to completion, to observe the effect of very low $\mathrm{pH}$ on the growth of $B$. cinerea RV05. EnzChek ${ }^{\circledR}$ assay analysis indicated that protease levels had been reduced, though not completely removed by the strong $\mathrm{pH}$ drop (data not shown). SDS-PAGE analysis revealed that the $\sim 78-\mathrm{kDa}$ band presumptively associated with laccase was not visible in samples collected in the hours following the drastic $\mathrm{pH}$ drop (Supplemental Fig. S1), suggesting that low $\mathrm{pH}$ treatment of $B$. cinerea culture medium could inactivate laccase activity while maintaining some protease activity.

\section{Analysis of protease production from $B$. cinerea B05.10 in 1-L bioreactors}

Protease production from B. cinerea B05.10 in 1-L bioreactors was also evaluated since it is an isolate used by many researchers worldwide, and successful production of protease with this isolate would increase the opportunity for reproduction of results in other laboratories. Fermentations were performed with the optimized conditions established with $B$. cinerea RV05 and compared with results from fermentation 4. Figure 4 shows the recorded protease amounts by EnzChek ${ }^{\circledR}$ assay during fermentation for both B. cinerea RV05 and B05.10. Single factor ANOVA analysis of protease recorded at all time points revealed that there was no statistical difference in protease production between isolates $(p$-value $=0.14)$. Single factor ANOVA

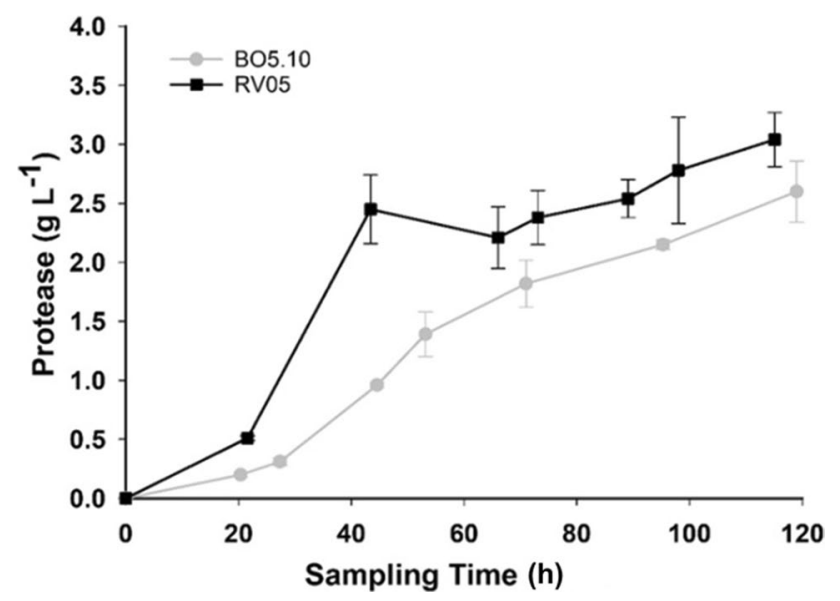

Fig. 4 Comparison of EnzChek ${ }^{\circledR}$ assay results for quantitation of protease production from $B$. cinerea RV05 and B05.10 cultured in soybean flour medium in 1-L bioreactors

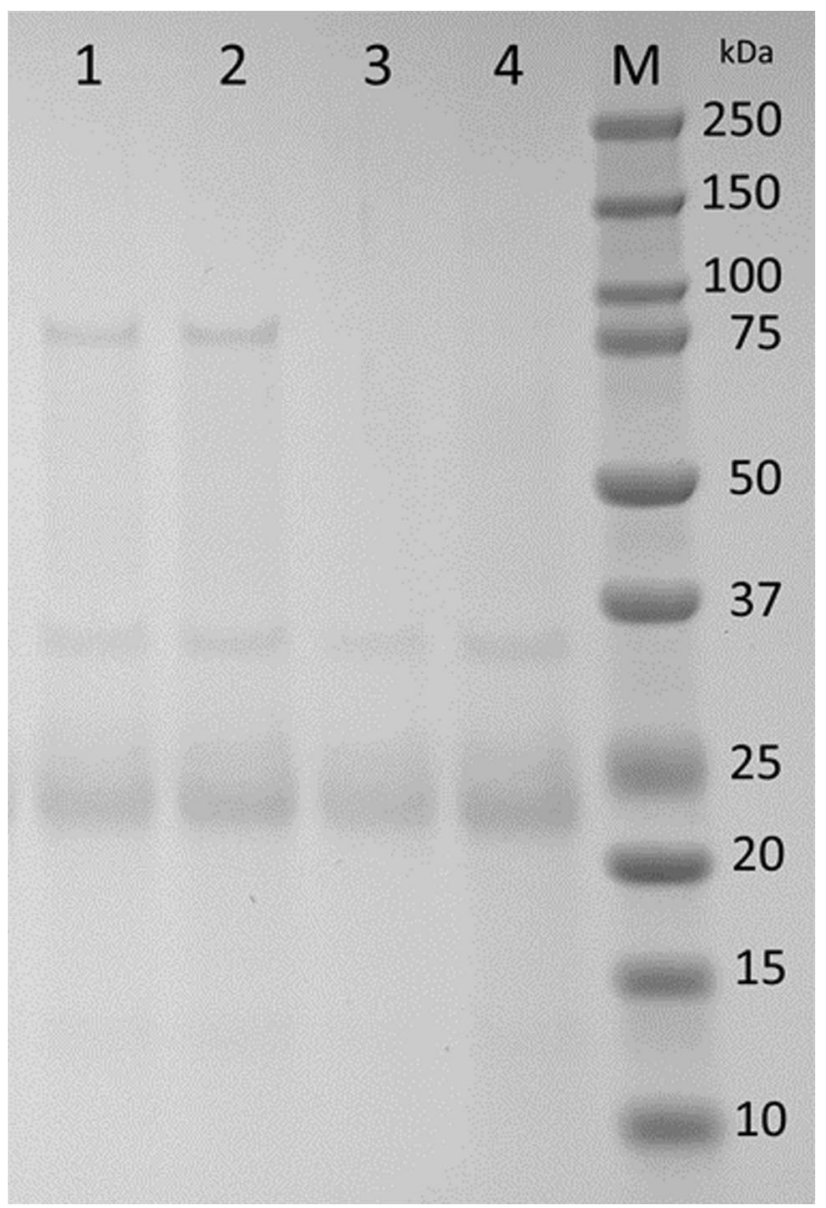

Fig. 5 Resolution of protease containing supernatant from $B$. cinerea fermentation using SDS-PAGE. Duplicate samples of $B$. cinerea supernatant before (lanes 1 and 2) and after (lanes 3 and 4) low pH treatment were resolved on a 4-12\% gradient gel. Lane M contains Bio-Rad Precision Plus Protein Dual Color Standard and the molecular masses $(\mathrm{kDa})$ of the markers are indicated on the right

of the maximum protease amount recorded at the end of fermentation indicated no statistical difference between isolates $(p$-value $=0.11)$. Two further fermentations were performed in parallel to confirm strong protease production from $B$. cinerea $\mathrm{B} 05.10$ in bioreactors. In replicate fermentations $\mathrm{B} 2$ and $\mathrm{B} 3$, the strong protease production from $B$. cinerea B05.10 continued, including the largest amount of protease recorded by EnzChek ${ }^{\circledR}$ assay in 1-L fermentations, of $3.60 \pm 0.9 \mathrm{~g} \mathrm{~L}^{-1}$ (Table 5).

\section{Inactivation of laccase with $\mathrm{pH}$ reduction}

The inactivation of laccase (while maintaining some protease activity) was analyzed by reducing aliquots of $B$. cinerea protease containing supernatant to $\mathrm{pH} 1.5$, then returning to $\mathrm{pH} 4.0$ after $1 \mathrm{~h}$. Resolution of the supernatant before and after the $\mathrm{pH}$ drop on SDS-PAGE indicates that 
the $\sim 75-\mathrm{kDa}$ band associated with laccase was not visible following $\mathrm{pH}$ treatment, while the $\sim 35-\mathrm{kDa}$ band associated with abundant $B$. cinerea protease BcAP8 was still visible (Fig. 5). Bands at $\sim 23 \mathrm{kDa}$ represent unidentified $B$. cinerea proteins that were also not degraded at $\mathrm{pH}$ 1.5. Quantification of protease activity by EnzChek® protease assay (in triplicate) indicated that after $\mathrm{pH}$ reduction, protease activity had been reduced from $2.02 \pm 0.24 \mathrm{~g} \mathrm{~L}^{-1}$ to $1.01 \pm 0.20 \mathrm{~g}$ $\mathrm{L}^{-1}$.

The re-activation of laccase when added to grape juice was analyzed by guaiacol assay, with overnight incubation. Positive controls and $B$. cinerea supernatant samples before $\mathrm{pH}$ reduction both measured end-point absorbance above the maximum $(4.32 \pm 0.0)$, while the protease supernatant reduced to $\mathrm{pH} 1.5 \mathrm{had}$ a negative reading $(-0.06 \pm 0.0)$ indicating that laccase was not re-activated when added to grape juice.

\section{Analyzing ammonium sulfate precipitation of $B$. cinerea secreted proteins}

Precipitation of proteases from the supernatant was analyzed with ammonium sulfate at 40, 60, and $80 \%$ (w/v) saturation. EnzChek $®$ assay results of $10-\mathrm{mL}$ experiments indicated that $0.8 \%$ of total active protease was collected at $40 \%$ ammonium sulfate saturation, $5.9 \%$ at $60 \%$ saturation, and $64.41 \%$ at $80 \%$ saturation. Ammonium sulfate precipitation at $80 \%$ saturation with $100-\mathrm{mL}$ volumes resulted in average protease yields of $66.63 \pm 6.2 \%$ in triplicate analyses.

\section{Identification of $B$. cinerea secreted proteins by mass spectrometry}

Peptides from $B$. cinerea proteins precipitated by ammonium sulfate were analyzed by mass spectrometry with SWATH acquisition and identified by comparison to a library of $B$. cinerea peptides. A total of 41 protein groups were identified in the B. cinerea protease mixture (Supplemental Table S2). The most abundant protein identified was glucoamylase, followed by aspartic protease BcAP8, serine peptidase, and glycoside hydrolase (peptide identifications, $n \geq 11$ ), all enzymes relating to cell wall degradation and virulence of B. cinerea (González-Fernández et al. 2014). Proteins with between 6 and 9 peptide identifications include sedolisin (serine protease), laccase-2, tripeptidyl-peptidase, carboxylic ester hydrolase, and glycoside hydrolase.

\section{Discussion}

Screening $B$. cinerea isolates for protease production on skim milk agar proved a reliable and simple method for identifying isolates that secreted proteolytic enzymes at $\mathrm{pH}$ 3.5.
Skim milk medium has been used to reliably identify proteolytic activity from Cladosporium and Trichoderma species amongst a cohort of filamentous fungi, using a similar rating to compare isolates (Nwadiaro et al. 2015). Guaiacol agar has also been used to identify filamentous fungi with laccase producing capacity, such as Trichoderma harzianum (Abd El Monssef et al. 2016), allowing simple identification of elite strains for further experimentation. The identification of a $B$. cinerea isolate that had simultaneously strong protease production and low laccase production was not achieved, though was also not likely as overall protein secretion has been linked to the virulence (and protease production) of a B. cinerea isolate (Fernández-Acero et al. 2007). Alternative carbon sources may have changed the secretion of protease or laccase from $B$. cinerea, which has been known to alter protein expression in relation to its environment (Liñeiro et al. 2016). More opportunities for modifying culture medium to illicit the desired response from $B$. cinerea were presented in small-scale liquid medium experiments.

Culturing the down selected $B$. cinerea isolates in SBF medium, with quantification of proteases by EnzChek ${ }^{\circledR}$ assay, proved a reliable method for identifying $B$. cinerea isolates with strong protease production. Soybean flour is a robust, cheap, and readily available nitrogen source for culturing fungi, which has been evaluated as a $\mathrm{N}$ source in cultures of various filamentous fungi to produce statins from Monascus and Aspergillus (Manzoni et al. 1999), proteases from thermophilic fungi (Macchione et al. 2008), and has been optimized for bioactive compound production in solid-state fermentation (Handa et al. 2019). Soybean protein (flour) was also identified as a good inducer of proteases production from $B$. cinerea when evaluating low-cost raw materials to produce alkaline proteases (Abidi et al. 2008). However, a more environmentally friendly and sustainable option for culturing $B$. cinerea isolates could be found by analyzing winery waste products as $\mathrm{C}$ and $\mathrm{N}$ sources. Large amounts of waste are produced at all stages of winemaking, including the remains from destemming and pressing grape berries, and sediment from clarification steps (Devesa-Rey et al. 2011). Grape vines and berries are a common target for B. cinerea (Ciliberti et al. 2016; Cotoras and Silva 2005; Dewey et al. 2008), so analyzing these waste products as a component of culture medium for the production of proteases from $B$. cinerea would be an ideal target for further investigation.

The inhibition of laccase in shake flask cultures was not achieved. Despite reports that concentrations of EDTA as low as $12 \mathrm{mM}$ had resulted in an absence of laccase in $B$. cinerea culture medium (Bar-Nun et al. 1988), laccase production was detected at every concentration of EDTA added to SBF medium. There was less laccase detected when no malic acid was used with EDTA; however, this coincided with almost no protease production. This result indicates 
that malic acid was being used as a nutrient source when added to the soybean flour medium for $\mathrm{pH}$ control. $\mathrm{CaCl}_{2}$ has been shown to reduce laccase when added to culture medium (Sansone et al. 2011), but strong laccase production from B. cinerea RV05 was observed when 1.68 and $72.08 \mathrm{mM}$ $\mathrm{CaCl}_{2}$ were added to shake flasks. While a comparatively reduced amount of laccase was observed in the shake flasks containing SBF and $144.16 \mathrm{mM} \mathrm{CaCl}_{2}$, even small amounts of laccase can have an adverse effect on the quality of wine (Zimdars et al. 2017), so complete removal or inhibition of laccase from $B$. cinerea isolates is required.

In shake flasks containing SBF medium, B. cinerea RV05 regularly produced more protease than reference strain $B$. cinerea $\mathrm{B} 05.10$. When malic acid was replaced with lactic acid for $\mathrm{pH}$ control, $\mathrm{B} 05.10$ produced more protease than previously, but still not as much as RV05. Other studies have identified $B$. cinerea $\mathrm{B} 05.10$ as a strong protein producer in comparison to two other wild-type $B$. cinerea isolates from grapes (Quijada-Morin et al. 2018), which implies that two strong protease producing strains of $B$. cinerea have been identified in this work.

Lactic acid proved a superior choice for $\mathrm{pH}$ control of $B$. cinerea culture medium than malic acid. Both malic and lactic acids are formed in the winemaking process (Wibowo et al. 1985), so are ideally suited for $\mathrm{pH}$ reduction in this work. Because the chemical structures of these acids vary, in that malic acid has two carboxyl groups and lactic acid only one, both the same concentration and double concentration of lactic acid compared to malic acid were tested. This allowed a direct comparison to both the equivalent molarity and buffering capacity of each acid. Analysis of carbon sources metabolized by $B$. cinerea using Biolog FF Microplates (Wang et al. 2016) found that both D- and L-malic acid were moderately metabolized by wild $B$. cinerea isolates, while L-lactic acid was not metabolized. The reduction in glucan production when lactic acid was used to control media $\mathrm{pH}$ was likely due to the inability of $B$. cinerea to metabolize the acid. Without additional substrate to feed the carbohydrate-rich glucan (Stahmann et al. 1995), the medium did not become as viscous as with malic acid, which increased the ease of sampling and made down-stream processing of samples more simple and efficient.

Scaling protease production from shake flask volumes to 1-L bioreactors presented the opportunity to increase both the volume and concentration of proteases produced by the $B$. cinerea isolates. The protease results from fermentation 1 (with no $\mathrm{pH}$ control) resulted in a 2 to $3 \times$ increase in protease secretion from RV05 in SBF medium. Subsequent fermentations identified that $B$. cinerea requires only acid addition to maintain the culture medium below $\mathrm{pH}$ 4. This has been observed in other research, where the fungus has been shown to adjust the $\mathrm{pH}$ of its environment to suit growth requirements (Billon-Grand et al. 2012; Manteau et al. 2003; Verhoeff et al. 1988).

Lactic acid was also analyzed for $\mathrm{pH}$ reduction in 1-L fermentations, as this acid had worked well in small-scale experiments. However, in fermentation 3, the culture medium turned very viscous after several days of culturing, with the return of lactic acid for $\mathrm{pH}$ control being the only chemical change introduced. This is curious since lactic acid had resulted in reduced culture viscosity in smallscale experiments, and B. cinerea has been shown not to metabolize lactic acid (Wang et al. 2016). Sulfuric acid was returned for $\mathrm{pH}$ control in fermentation 4 (Eppendorf 2012), and resulted in less viscous culture medium in 1-L $B$. cinerea fermentations. With this final change, protease levels were the highest recorded with over $3 \mathrm{~g} \mathrm{~L}^{-1}$ produced by the end of the fermentation, for a tenfold increase on the maximum protease amounts produced by $B$. cinerea RV05 in small-scale experiments.

The difference in quantified protease levels in the more viscous fermentation with lactic acid could be due to the protease and other metabolites produced by $B$. cinerea being trapped inside the glucan rich biomass, instead of dissolving in the small amount of free-flowing medium in the vessel. This sequestering of metabolites in $B$. cinerea culture medium has been observed in previous studies, when $\beta$-1,3-glucanase was added to culture medium to reduce the viscosity, resulting in an observed increase in laccase activity (Gil-ad et al. 2001). However, this was coupled with an increase in laccase activity; not an ideal outcome when laccase activity is not desired.

B. cinerea B05.10 was ultimately selected as the strain to continue scale up work, and steadily produced high levels of protease across three 1-L fermentations. B. cinerea B05.10 has been used in many different experimental contexts, from transcriptome profiling (Srivastava et al. 2020) to morphological growth analyses (Zhou et al. 2018), and has had its entire genome sequenced (Amselem et al. 2011; Van Kan et al. 2016). B. cinerea B05.10 has also been used in labs across the world, as it has maintained sterility and virility with a reduced nuclear number (Tudzynski and Siewers 2007). B. cinerea B05.10 showed continued strong protease production in 1-L bioreactors, also showing a greater than 10 times increase from protease levels observed in shake flasks.

A major aim in this work was to inactivate or remove laccase from the protease in culture medium. The accidental, drastic reduction in $\mathrm{pH}$ during an early $1-\mathrm{L}$ fermentation provided insight that $B$. cinerea laccase could be denatured by decreasing the medium $\mathrm{pH}$ close to $\mathrm{pH} 1$. Indeed, it has been discovered that $B$. cinerea laccase will be irreversibly denatured below pH 2.5 (Dubernet et al. 1977). Analysis of $B$. cinerea expressed proteins by SDS-PAGE enabled simple conformation of the absence of laccase from the analyzed sample, and is a method used for analysis of $B$. 
cinerea proteins by other researchers (Marchal et al. 2020; Shah et al. 2009).

The possibility of re-activation of laccase was assessed by incubating samples overnight at room temperature, with guaiacol as the indicator. The extended incubation period allowed for any laccase present to be re-activated and detected by a color change of guaiacol from clear to deep red brown. No laccase activity was detected in any of the protease samples after addition to grape juice, confirming that laccase had been inactivated in the $B$. cinerea culture medium.

The proteins present in the ammonium sulfate fraction from $B$. cinerea were identified by SWATH-MS. Since the protease preparation was reduced to $\mathrm{pH} 1.5$ prior to ammonium sulfate precipitation, it is not certain that any of the proteases identified by SWATH-MS were able to maintain enzymatic activity and contribute to the overall protease activity recorded in the final product. However, the EnzChek ${ }^{\circledR}$ protease assay used for quantifying protease activity in the samples will detect metallo, serine, sulfhydryl, and acid proteases (BcAP8) (Probes 2004). Therefore, while it is likely that most of the protease activity detected in the $B$. cinerea protease mixture was BcAP8, as it is the most abundant protein in the $B$. cinerea secretome and in this sample (Espino et al. 2010; Ten Have et al. 2010) and known to be active at low $\mathrm{pH}$, it is possible that serine and metallo-proteases also added to the protease activity detected by EnzChek $®$ assay.

Previous studies of the $B$. cinerea proteome have identified differences in protein expression and secretion with differing substrates, whether in liquid or solid cultures (Shah et al. 2009), and also at different pH (Li et al. 2012). The $B$. cinerea culture from which these proteins were collected was maintained at $\mathrm{pH} 4$, which has been shown to induce secretion of proteases that counter the host's pathogenesis response rather than proteases aimed at cell wall degradation (González-Fernández et al. 2015). While the most abundant protein identified in the $B$. cinerea protease mixture was glucoamylase, a plant cell wall degrading enzyme ( $\mathrm{Li}$ et al. 2020), which has been identified in high abundance from $B$. cinerea $\mathrm{B} 05.10$ by other researchers (González-Fernández et al. 2014), most of the proteins identified by 5 or more peptides were proteases. Finally, the identification of laccase- 2 in the protease cocktail is not concerning but highlights that $80 \%$ ammonium sulfate precipitation collected all the proteins and protein fragments (whether active or inactivated) present in the $B$. cinerea protease mixture.

Through the screening, down selection, and optimization of culture medium, two $B$. cinerea strains with strong protease production have been identified. Scale up of production from $250-\mathrm{mL}$ shake flasks to $1-\mathrm{L}$ bioreactors increased protease yield over 10 times. The precipitation of proteases with $80 \%$ ammonium sulfate resulted in the preparation of a simple protease cocktail with the potential to degrade winehaze forming proteins and reduce the use of bentonite in the winemaking process.

Supplementary Information The online version contains supplementary material available at https://doi.org/10.1007/s00253-022-11817-1.

Acknowledgements Acknowledgement to the Central Analytical Research Facility (CARF), Queensland University of Technology, for use of their facilities.

Author contribution SVS, JT, and RS conceived and designed research, and conducted analyses. RS conducted experiments and undertook analyses, and RS and MH wrote the manuscript. All authors read and approved the manuscript.

Funding Open Access funding enabled and organized by CAUL and its Member Institutions. Partial financial support was received from Macquarie University, Sydney, Australia, through the Research Training Pathway Scholarship. The remainder of this research was supported by funding from Wine Australia under Grant agreement number AGW Ph1511. Wine Australia invests in and manages research, development, and extension on behalf of Australia's grape growers and winemakers and the Australian Government.

Availability of data and material The datasets generated during and/or analyzed during the current study are available from the corresponding author on reasonable request.

\section{Declarations}

Ethical approval This article does not contain any studies with human participants or animals performed by any of the authors.

Conflict of interest Author 1 declares that the data presented in this manuscript is from her doctoral dissertation, submitted to Macquarie University, New South Wales, Australia, on 4th July 2019. The thesis is not currently published online or accessible by the public. The author has no conflicts of interest to disclose. Authors 2 to 4 declare that they have no conflict of interest.

Open Access This article is licensed under a Creative Commons Attribution 4.0 International License, which permits use, sharing, adaptation, distribution and reproduction in any medium or format, as long as you give appropriate credit to the original author(s) and the source, provide a link to the Creative Commons licence, and indicate if changes were made. The images or other third party material in this article are included in the article's Creative Commons licence, unless indicated otherwise in a credit line to the material. If material is not included in the article's Creative Commons licence and your intended use is not permitted by statutory regulation or exceeds the permitted use, you will need to obtain permission directly from the copyright holder. To view a copy of this licence, visit http://creativecommons.org/licenses/by/4.0/.

\section{References}

Abd El Monssef RA, Hassan EA, Ramadan EM (2016) Production of laccase enzyme for their potential application to decolorize fungal 
pigments on aging paper and parchment. Ann Ag Sci 61(1):145154. https://doi.org/10.1016/j.aoas.2015.11.007

Abidi F, Limam F, Nejib MM (2008) Production of alkaline proteases by Botrytis cinerea using economic raw materials: assay as biodetergent. Proc Biochem 43(11):1202-1208. https://doi.org/10. 1016/j.procbio.2008.06.018

Amselem J, Cuomo CA, van Kan JA, Viaud M, Benito EP, Couloux A, Coutinho PM, de Vries RP, Dyer PS, Fillinger S (2011) Genomic analysis of the necrotrophic fungal pathogens Sclerotinia sclerotiorum and Botrytis cinerea. PLoS Genet 7(8). https://doi.org/10. 1371/journal.pgen.1002230

Bar-Nun N, Tal Lev A, Harel E, Mayer AM (1988) Repression of laccase formation in Botrytis cinerea and its possible relation to phytopathogenicity. Phytochem 27(8):2505-2509. https://doi.org/10. 1016/0031-9422(88)87018-3

Bar-Nun N, l'Hyvernay A, Donèche B, Mayer A (2007) Changes in mycelial structure of Botrytis cinerea induced by removal of the glucan matrix. J Sci Vigne Vin 41(3): 149. https://doi.org/10. 20870/oeno-one.2007.41.3.843

Billon-Grand G, Rascle C, Droux M, Rollins JA, Poussereau N (2012) $\mathrm{pH}$ modulation differs during sunflower cotyledon colonization by the two closely related necrotrophic fungi Botrytis cinerea and Sclerotinia sclerotiorum. Mol Plant Pathol 13(6):568-578. https:// doi.org/10.1111/j.1364-3703.2011.00772.x

Burgess RR (2009) Protein precipitation techniques. Methods in enzymology, vol 463. Elsevier, Amsterdam, pp 331-342

Büttner P, Koch F, Voigt K, Quidde T, Risch S, Blaich R, Brückner B, Tudzynski P (1994) Variations in ploidy among isolates of Botrytis cinerea: implications for genetic and molecular analyses. Curr Genet 25(5):445-450. https://doi.org/10.1007/BF00351784

Chambers PJ, Pretorius IS (2010) Fermenting knowledge: the history of winemaking, science and yeast research. EMBO Rep 11(12):914920. https://doi.org/10.1038/embor.2010.179

Chardonnet CO, Sams CE, Trigiano RN, Conway WS (2000) Variability of three isolates of Botrytis cinerea affects the inhibitory effects of calcium on this fungus. Phytopath 90(7):769-774. https://doi.org/10.1094/PHYTO.2000.90.7.769

Chemonges S, Gupta R, Mills PC, Kopp SR, Sadowski P (2017) Characterisation of the circulating acellular proteome of healthy sheep using LC-MS/MS-based proteomics analysis of serum. Proteome Sci 15(1):1-16. https://doi.org/10.1186/s12953-017-0119-z

Ciliberti N, Fermaud M, Roudet J, Languasco L, Rossi V (2016) Environmental effects on the production of Botrytis cinerea conidia on different media, grape bunch trash, and mature berries. Aust J Grape Wine Res 22(2):262-270. https://doi.org/10.1111/ajgw. 12217

Claus H (2017) Laccases of Botrytis cinerea. In: König H, Unden G, Fröhlich J (eds) Biology of microorganisms on grapes, in must and in wine. Springer International Publishing, pp. 339-356. https:// doi.org/10.1007/978-3-319-60021-5_14

Cotoras M, Silva E (2005) Differences in the initial events of infection of Botrytis cinerea strains isolated from tomato and grape. Mycologia 97(2):485-492. https://doi.org/10.3852/mycologia.97.2.485

Cotoras M, García C, Mendoza L (2009) Botrytis cinerea isolates collected from grapes present different requirements for conidia germination. Mycologia 101(3):287-295. https://doi.org/10.3852/ 08-012

Devesa-Rey R, Vecino X, Varela-Alende JL, Barral MT, Cruz JM, Moldes AB (2011) Valorization of winery waste vs. the costs of not recycling. Waste Manag 31(11):2327-2335. https://doi.org/ 10.1016/j.wasman.2011.06.001

Dewey FM, Hill M, DeScenzo R (2008) Quantification of Botrytis and laccase in winegrapes. Am J Enol Vitic 59(1): 47-54. http://www. ajevonline.org/content/59/1/47.abstract

Doss RP (1999) Composition and enzymatic activity of the extracellular matrix secreted by germlings of Botrytis cinerea. Appl
Environ Microbiol 65(2):404-408. https://doi.org/10.1128/AEM. 65.2.404-408.1999

Dubernet M, Ribereau-Gayon P, Lerner HR, Harel E, Mayer AM (1977) Purification and properties of laccase from Botrytis cinerea. Phytochem 16(2):191-193. https://doi.org/10.1016/ S0031-9422(00)86783-7

Eppendorf (2012) New Brunswick BioFlo®/CelliGen ${ }^{\circledR} 115$ benchtop fermentor \& bioreactor - operating manual. Accessed April 2017 from https://physiology.case.edu/media/eq_manuals/eq_manual_ eppendorf_bioFlo_celligen_115.pdf

Escher C, Reiter L, MacLean B, Ossola R, Herzo F, Chilton J, MacCoss MJ, Rinner O (2012) Using i RT, a normalized retention time for more targeted measurement of peptides. Proteomics 12(8):11111121. https://doi.org/10.1002/pmic.201100463

Espino JJ, Gutiérrez-Sánchez G, Brito N, Shah P, Orlando R, González C (2010) The Botrytis cinerea early secretome. Proteomics 10(16):3020-3034. https://doi.org/10.1002/pmic.201000037

Fernández-Acero FJ, Jorge I, Calvo E, Vallejo I, Carbú M, Camafeita E, Garrido C, López JA, Jorrin J, Cantoral JM (2007) Proteomic analysis of phytopathogenic fungus Botrytis cinerea as a potential tool for identifying pathogenicity factors, therapeutic targets and for basic research. Arch Microbiol 187(3):207-215. https://doi. org/10.1007/s00203-006-0188-3

Flores J, Heatherbell D, McDaniel M (1990) Ultrafiltration of wine: effect of ultrafiltration on white Riesling and Gewürztraminer wine composition and stability. Am J Enol Vitic 41(3):207-214

Gil-ad NL, Bar-Nun N, Mayer AM (2001) The possible function of the glucan sheath of Botrytis cinerea: effects on the distribution of enzyme activities. FEMS Microbiol Lett 199(1):109-113. https:// doi.org/10.1111/j.1574-6968.2001.tb10659.x

Gillet LC, Navarro P, Tate S, Röst H, Selevsek N, Reiter L, Bonner R, Aebersold R (2012) Targeted data extraction of the MS/MS spectra generated by data-independent acquisition: a new concept for consistent and accurate proteome analysis. Mol Cell Proteomics 11(6): O111. 016717. https://doi.org/10.1074/mcp.O111.016717

González-Fernández R, Aloria K, Valero-Galván J, Redondo I, Arizmendi JM, Jorrín-Novo JV (2014) Proteomic analysis of mycelium and secretome of different Botrytis cinerea wild-type strains. J Proteomics 97:195-221. https://doi.org/10.1016/j.jprot.2013.06. 022

González-Fernández R, Valero-Galván J, Gómez-Gálvez FJ, JorrínNovo JV (2015) Unraveling the in vitro secretome of the phytopathogen Botrytis cinerea to understand the interaction with its hosts. Front Plant Sci 6. https://doi.org/10.3389/fpls.2015.00839

Handa CL, de Lima FS, Guelfi MFG, da Silva FM, Georgetti SR, Ida EI (2019) Parameters of the fermentation of soybean flour by Monascus purpureus or Aspergillus oryzae on the production of bioactive compounds and antioxidant activity. Food Chem 271:274-283. https://doi.org/10.1016/j.foodchem.2018.07.188

Kiiskinen LL, Rättö M, Kruus K (2004) Screening for novel laccaseproducing microbes. J Appl Microbiol 97(3):640-646. https://doi. org/10.1111/j.1365-2672.2004.02348.x

King AD, Camirand WM, Mihara KL (1969) Submerged-culture production of Botrytis cinerea mycelium. Am J Enol Vitic 20(3):146-151

Leal JA, Rupérez P, Gomez-Miranda B (1979) Extracellular glucan production by Botrytis cinerea. Trans Brit Mycol Soc 72(1):172176. https://doi.org/10.1016/S0007-1536(79)80026-1

Li A, Zhu Y, Xu L, Zhu W, Tian X (2008) Comparative study on the determination of assay for laccase of Trametes sp. Afr J Biochem Res 2(8):181-183

Li B, Wang W, Zong Y, Qin G, Tian S (2012) Exploring pathogenic mechanisms of Botrytis cinerea secretome under different ambient $\mathrm{pH}$ based on comparative proteomic analysis. J Proteome Res 11(8):4249-4260. https://doi.org/10.1021/pr300365f 
Li H, Zhang Z, Qin G, He C, Li B, Tian S (2020) Actin is required for cellular development and virulence of Botrytis cinerea via the mediation of secretory proteins. Msystems 5(1):e00732-e719. https://doi.org/10.1128/mSystems.00732-19

Liñeiro E, Chiva C, Cantoral JM, Sabidó E, Fernández-Acero FJ (2016) Modifications of fungal membrane proteins profile under pathogenicity induction: a proteomic analysis of Botrytis cinerea membranome. Proteomics 16(17):2363-2376. https://doi.org/10. 1002/pmic.201500496

Liñeiro E, Macias-Sánchez AJ, Espinazo M, Cantoral JM, Moraga J, Collado IG, Fernández-Acero FJ (2018) Phenotypic effects and inhibition of botrydial biosynthesis induced by different plantbased elicitors in Botrytis cinerea. Curr Microbiol 75(4):431-440. https://doi.org/10.1007/s00284-017-1399-3

Logan S (2015) Wine finishing: brilliant ideas for alternatives to bentonite-progress and payoffs. Wine Vitic J 30(2):33

Logan S (2018) Wine making: winery innovations: Australian wineries increase uptake of crossflow filtration and flotation but should they embrace more technologies? Aust NZ Grapegrow Winemak 656:54

Lovato A, Zenoni S, Tornielli GB, Colombo T, Vandelle E, Polverari A (2019) Specific molecular interactions between Vitis vinifera and Botrytis cinerea are required for noble rot development in grape berries. Postharvest Biol Technol 156:110924. https://doi.org/10. 1016/j.postharvbio.2019.05.025

Macchione MM, Merheb CW, Gomes E, Da Silva R (2008) Protease production by different thermophilic fungi. Appl Biochem Biotechnol 146(1):223-230

Majewski P, Barbalet A, Waters E (2011) \$1 billion hidden cost of bentonite fining. Aust NZ Grapegrow Winemak 569:58-62

Manteau S, Abouna S, Lambert B, Legendre L (2003) Differential regulation by ambient $\mathrm{pH}$ of putative virulence factor secretion by the phytopathogenic fungus Botrytis cinerea. FEMS Microbiol Ecol 43(3):359-366. https://doi.org/10.1111/j.1574-6941.2003. tb01076.x

Manzoni M, Bergomi S, Rollini M, Cavazzoni V (1999) Production of statins by filamentous fungi. Biotechnol Lett 21(3):253-257

Marangon M, Van Sluyter SC, Haynes PA, Waters EJ (2009) Grape and wine proteins: their fractionation by hydrophobic interaction chromatography and identification by chromatographic and proteomic analysis. J Agric Food Chem 57(10):4415-4425. https:// doi.org/10.1021/jf9000742

Marangon M, Lucchetta M, Waters EJ (2011) Protein stabilisation of white wines using zirconium dioxide enclosed in a metallic cage. Aust J Grape Wine Res 17(1):28-35. https://doi.org/10.1111/j. 1755-0238.2010.00112.x

Marangon M, Van Sluyter SC, Robinson E, Muhlack RA, Holt HE, Haynes PA, Godden PW, Smith PA, Waters EJ (2012) Degradation of white wine haze proteins by Aspergillopepsin I and II during juice flash pasteurization. Food Chem 135(3):1157-1165. https://doi.org/10.1016/j.foodchem.2012.05.042

Marchal R, Salmon T, Gonzalez R, Kemp B, Vrigneau C. Williams P, Doco T (2020) Impact of Botrytis cinerea contamination on the characteristics and foamability of yeast macromolecules released during the alcoholic fermentation of a model grape juice. Molecules 25(3): 472. https://www.mdpi.com/1420-3049/25/3/472

Miclea RV, Puia CE (2012) In vitro studies regarding the biology and the biological control of some Botrytis cinerea Pers. isolates. Bull Univ Agric Sci Vet Med Cluj-Napoca Agric 69(1):300-301

Mienda BS, Yahya A, Galadima IA, Shamsir MS (2014) An overview of microbial proteases for industrial applications. Res J Pharm Biol Chem Sci 5(1):388-396

Nevalainen H, Kautto L, Te'o J (2014) Methods for isolation and cultivation of filamentous fungi. Environ Microbiol. Humana Press, New Jersey, pp 3-16
Nwadiaro P, Ogbonna A, Wuyep P, Adekojo D (2015) Keratinolytic activity of Cladosporium and Trichoderma species isolated from barbers' landfill. Int J Biosci. https://doi.org/10.12692/ijb/6. 105-115

Pielken P, Stahmann P, Sahm H (1990) Increase in glucan formation by Botrytis cinerea and analysis of the adherent glucan. App Microbiol Biotechnol 33(1):1-6

Probes M (2004) EnzChek ${ }^{(\mathrm{R})}$ Protease Assay Kits - product information. Invitrogen, accessed April 2016 from https://www.therm ofisher.com/document-connect/document-connect.html?url= https\%3A\%2F\%2Fassets.thermofisher.com\%2FTFS-Assets\% 2FLSG\%2Fmanuals\%2Fmp06638.pdf\&title=RW56Q2hlay BQcm90ZWFzZSBBc3NheSBLaXQ=

Quijada-Morin N, Garcia F, Lambert K, Walker AS, Tiers L, Viaud M, Sauvage FX, Hirtz C, Saucier C (2018) Strain effect on extracellular laccase activities from Botrytis cinerea. Aust J Grape Wine Res 24(2):241-251. https://doi.org/10.1111/ajgw.12322

Rajamani S, Hilda A (1987) Plate assay to screen fungi for proteolytic activity. Curr Sci Bangalore 56(22):1179-1181

Ratnayake S, Stockdale V, Grafton S, Munro P, Robinson AL, Pearson W, McRae J, Bacic A (2019) Carrageenans as heat stabilisers of white wine. Aust J Grape Wine Res 25(4):439-450. https://doi. org/10.1111/ajgw.12411

Sansone G, Rezza I, Fernández G, Calvente V, Benuzzi D, Sanz MI (2011) Inhibitors of polygalacturonase and laccase of Botrytis cinerea and their application to the control of this fungus. Int Biodeterior Biodegrad 65(1):243-247. https://doi.org/10.1016/j. ibiod.2010.09.010

Sarmento MR, Oliveira JC, Boulton RB (2000) Selection of low swelling materials for protein adsorption from white wines. Int J Food Sci Technol 35(1):41-47. https://doi.org/10.1046/j.13652621.2000.00340.x

Shah P, Atwood JA, Orlando R, El Mubarek H, Podila GK, Davis MR (2009) Comparative proteomic analysis of Botrytis cinerea secretome. J Proteome Res 8(3):1123-1130. https://doi.org/10. $1021 /$ pr8003002

Srivastava DA, Arya GC, Pandaranayaka EP, Manasherova E, Prusky DB, Elad Y, Frenkel O, Harel A (2020) Transcriptome profiling data of Botrytis cinerea infection on whole plant Solanum lycopersicum. Mol Plant Microbe Interact 33(9):1103-1107. https:// doi.org/10.1094/mpmi-05-20-0109-a

Stahmann KP, Monschau N, Sahm H, Koschel A, Gawronski M, Conrad H, Springer T, Kopp F (1995) Structural properties of native and sonicated cinerean, a $\beta-(1-3)(1-6)-D$-glucan produced by Botrytis cinerea. Carbohydr Res 266(1):115-128. https://doi.org/10.1016/0008-6215(94)00245-B

Steel CC, Blackman JW, Schmidtke LM (2013) Grapevine bunch rots: impacts on wine composition, quality, and potential procedures for the removal of wine faults. J Agric Food Chem 61(22):5189-5206. https://doi.org/10.1021/jf400641r

Ten Have A, Dekkers E, Kay J, Phylip LH, van Kan JA (2004) An aspartic proteinase gene family in the filamentous fungus Botrytis cinerea contains members with novel features. Microbiology 150(7):2475-2489. https://doi.org/10.1099/mic.0.27058-0

Ten Have A, Espino JJ, Dekkers E, Van Sluyter SC, Brito N, Kay J, González C, van Kan JA (2010) The Botrytis cinerea aspartic proteinase family. Fungal Genet Biol 47(1):53-65. https://doi. org/10.1016/j.fgb.2009.10.008

Tudzynski P, Siewers V (2007) Approaches to molecular genetics and genomics of Botrytis. In: Elad Y, Williamson B, Tudzynski P, Delen N (eds) Botrytis: biology, pathology and control. Springer Science \& Business Media, Berlin, pp 53-66

Van Kan JA (2006) Licensed to kill: the lifestyle of a necrotrophic plant pathogen. Trends Plant Sci 11(5):247-253. https://doi.org/ 10.1016/j.tplants.2006.03.005 
Van Kan JA, Stassen JH, Mosbach A, Van der Lee TA, Faino L, Farmer AD, Papasotiriou D, Zhou S, Seidl MF, Cottam E (2016) A gapless genome sequence of the fungus Botrytis cinerea. Mol Plant Pathol 18(1):75-89. https://doi.org/10.1111/mpp.12384

Van Sluyter SC, Warnock NI, Schmidt S, Anderson P, Van Kan JA, Bacic A, Waters EJ (2013) Aspartic acid protease from Botrytis cinerea removes haze-forming proteins during white winemaking. J Agric Food Chem 61(40):9705-9711. https://doi.org/10. $1021 / \mathrm{jf} 402762 \mathrm{k}$

Vela E, Hernández-Orte P, Castro E, Ferreira V, Lopez R (2017) Effect of bentonite fining on polyfunctional mercaptans and other volatile compounds in Sauvignon blanc wines. Am J Enol Vitic 68(1):30. https://doi.org/10.5344/ajev.2016.16052

Verhoeff K, Leeman M, Peer R, Posthuma L, Schot N, Eijk G (1988) Changes in $\mathrm{pH}$ and the production of organic acids during colonization of tomato petioles by Botrytis cinerea. J Phytopathol 122(4):327-336. https://doi.org/10.1111/j.1439-0434.1988. tb01024.x

Vignault A, Gombau J, Jourdes M, Moine V, Canals JM, Fermaud M, Roudet J, Zamora F, Teissedre PL (2020) Oenological tannins to prevent Botrytis cinerea damage in grapes and musts: kinetics and electrophoresis characterization of laccase. Food Chem 316:126334. https://doi.org/10.1016/j.foodchem.2020.126334

Wang H, Wang J, Li L, Hsiang T, Wang M, Shang S, Yu Z (2016) Metabolic activities of five botryticides against Botrytis cinerea examined using the Biolog FF MicroPlate. Sci Rep 6

Waters EJ, Shirley NJ, Williams PJ (1996) Nuisance proteins of wine are grape pathogenesis-related poteins. J Agric Food Chem 44(1):3-5. https://doi.org/10.1021/jf9505584
Waters EJ, Alexander G, Muhlack R, Pocock KF, Colby C, Oneill BK, Høj PB, Jones P (2005) Preventing protein haze in bottled white wine. Aust J Grape Wine Res 11(2):215-225. https://doi.org/10. 1111/j.1755-0238.2005.tb00289.x

Wessel D, Flügge UI (1984) A method for the quantitative recovery of protein in dilute solution in the presence of detergents and lipids. Anal Biochem 138(1):141-143

Wibowo D, Eschenbruch R, Davis CR, Fleet GH, Lee TH (1985) Occurrence and growth of lactic acid bacteria in wine: a review. Am J Enol Vitic 36(4): 302. http://www.ajevonline.org/content/ 36/4/302.abstract

Zhou Y, Li N, Yang J, Yang L, Wu M, Chen W, Li G, Zhang J (2018) Contrast between orange- and black-colored sclerotial isolates of Botrytis cinerea: melanogenesis and ecological fitness. Plant Dis 102(2):428-436. https://doi.org/10.1094/pdis-11-16-1663-re

Zimdars S, Hitschler J, Schieber A, Weber F (2017) Oxidation of wine polyphenols by secretomes of wild Botrytis cinerea strains from white and red grape varieties and determination of their specific laccase activity. J Agric Food Chem 65(48):10582-10590. https:// doi.org/10.1021/acs.jafc.7b04375

Zouari N, Romette JL, Thomas D (1987) Purification and properties of two laccase isoenzymes produced by Botrytis cinerea. Appl Biochem Biotechnol 15(3):213-225

Publisher's Note Springer Nature remains neutral with regard to jurisdictional claims in published maps and institutional affiliations. 